\title{
Serious Case Reviews: The Lived Experience of Black Children
}

Abstract

Despite the many high-profile black child deaths in England, race as a factor remains a largely under-explored factor of Serious Case Reviews (SCRs). Evidence from analysis of SCRs indicates that race receives limited attention, or is virtually absent. Given that the main function of SCRs is to provide opportunities for learning lessons to improve practice, the way in which issues of race and culture may influence child protection processes for black children is therefore of critical importance. In this article, we employ content analysis to examine the extent that race and cultural factors are considered in SCRs involving black children. It is argued that race is often an important factor influencing black children's experiences of abuse and neglect, as well as their encounters in the child protection system. This article therefore poses two key questions: 1) What questions are asked about race, ethnicity and culture in SCRs concerning black children? 2) How did the SCRs extract lessons to be learnt for improving practice to safeguard black children? By extending the analysis of race and ethnicity in SCRs, this article furthers our understandings of the needs of black children in the child protection system.

Keywords: Serious Case Reviews, Race and Cultural factors, Black Children, Child Protection 


\section{Introduction}

This paper explores how race, culture and ethnicity are addressed in Serious Case Reviews (hereafter referred to as SCRs). These elements are explored through an investigation of a number of recent SCRs using tools from content analysis to explore key areas pertinent to black children's day-to-day lived experience. Throughout, black is used to refer to individuals of African and African-Caribbean origin as well as persons of mixed ethnicity (African or African-Caribbean and another parentage, usually white British). In the paper we begin by providing an overview of key issues emerging from past SCRs concerning black children. The paper then explores some key themes to understand how race, culture and ethnicity are addressed in recent SCRs. We conclude with a consideration of the implications for practice.

\section{Setting the context}

In England, a number of high-profile child death inquiries concern black children (Blom-Cooper, 1985; London Borough of Lambeth, 1987; Newham Area Child Protection Committee, 2002; Laming, 2003; Barn, 2007). An SCR takes place in England when serious or fatal violence or maltreatment of a child has taken place, including when a child or young person dies in custody. This involves the Local Safeguarding Children Board commissioning a detailed examination of the case to establish whether there are lessons to be learned about the ways in which professionals and organisations work together to safeguard children and promote their welfare. Both good practice and areas of concern are identified, although there are a 
number of barriers to embedding this learning in policy and practice (Rawlings et al., 2014).

There is evidence to show that in a proportion of child deaths and child protection plans, the ethnicity and asylum-seeking status of children is not known (Brandon et al., 2012; DfE, 2013), and that the ethnicity will be unrecorded or not identified in some SCRs (Sidebotham et al., 2016). While analysis of earlier SCRs suggested that black children are over-represented, especially mixed-ethnicity children (Brandon et al., 2009, 2012), a review of SCRs published between 2011-2014 has not found this over-representation; black children were $6 \%$ and mixed-ethnicity children $8 \%$ (Sidebotham et al., 2016).

Recent high-profile child death inquiries highlight particular issues for safeguarding black children, including risk factors and harmful practices (Laming, 2003; Radford, 2010; Wate, 2017). For example, a number of commentators on the Laming report on Victoria Climbié who died in 2000, highlighted some key issues, including the impact of globalization and international considerations, the vulnerability of privatelyfostered children, and misinformation about Victoria's identity as well as her relationship to her carer, Marie-Therese Kouao (Laming, 2003; Parton, 2004; BhattiSinclair \& Price, 2016; Barn \& Kirton, 2016). Furthermore, Laming (2003) drew attention to her carer's belief in spirit possession, the failure to speak with Victoria on her own and in her native language, as well as practitioners' erroneous assumptions about culture, involving racism and culturally-based stereotypes. However, the Laming report has been criticised for not analysing the role of race in interactions between professionals, and for failing to consider the wider context surrounding 
migration and refugees in England (Chand, 2003; Rustin, 2004; Garrett. 2006; BRAP, 2011). Other general concerns regarding SCRs include the infrequency of recommendations regarding culture and ethnicity (Brandon et al., 2012), and the need to understand both the human processes, and the organisational and inter-personal dynamics that result in poor practice (Jones, 2015).

Bhatti-Sinclair \& Price (2016) used content analysis to examine the extent to which issues of culture, language, religion and ethnicity are incorporated into the findings of SCRs published between 1991-2010. Three key themes were identified: 1) the value of the NSPCC's national online repository of published SCRs for gathering data on the voice of black children and social inequalities; 2) The absence of data on family demographic characteristics and inconsistency in the recording of ethnicity, religion, culture and language; and 3) The absence of in-depth analysis of and sensitivity to diversity including professionals holding biased views regarding living standards. Due to the inconsistency in recording of ethnicity, culture and religion, Bhatti-Sinclair \& Price (2016) indicated no conclusions could be drawn.

\section{Method}

The search strategy for the review utilised electronic databases and web-based online search engines. As Bhatti-Sinclair \& Price (2016) have already undertaken some work on black children and SCRs, published between 1991 and 2010, we limited our review to SCRs published since 2010. In order to review the range of available evidence, searches were conducted via the electronic databases of the NSPCC Case Review Repository, which provided a chronological list of the executive summaries or full overview reports published in a given year. In addition, all the 
Local Safeguarding Children Boards (LSCBs) in England were searched, together with the Association of Independent LSCB Chairs, as well as the DfE's Child Death Review platform. Because of the inconsistency in the way that ethnicity is recorded, we had to use a range of concepts to identify ethnic data in our searches. Key search terms were used to broaden the search, including: African, Caribbean, race, ethnicity, black, culture, religion, language, interpreter, racism, mixed heritage, dual heritage and transracial. The inclusion criteria for the review included the child's age and gender, the categories of maltreatment, geographical location, and with whom the child was residing. A number of SCRs that have received widespread media coverage were selected, together with a number of SCRs from the NSPCC repository of SCRs during the period under review. The sample consisted of 14 SCRs of children ranging in age from 4 months to 17 years and included both males and females. The SCRs reviewed were from across England and covered different categories of abuse, including children that were on a child protection plan or other statutory order, children living with their families, and children who were looked-after. In those highprofile cases that had received a lot of media attention, the name of the child is used, whilst others refer to the child by their initials. Table 1 gives a breakdown of the SCRs reviewed.

We drew on some of the techniques from qualitative content analysis to analyse the SCRs. Our aim in using qualitative content analysis was to focus on themes and underlying messages within the text rather than only focusing on word counts or terminology (Hsieh \& Shannon, 2005; Zhang \& Wildemuth, 2017). As a key focus of our reading was to identify how race, ethnicity and cultural factors were examined in the assessments to gain a picture of children's circumstances, we employed 
qualitative content analysis, an approach that is useful for texts that are complex, sensitive and emotive (Rapport, 2010). Two specific questions guided an initial reading of the SCRs. 1) What are the questions asked about race, ethnicity and cultural factors in SCRs concerning black children? 2) How did the SCRs extract lessons to be learnt for improving practice to safeguard black children? Each SCR was carefully read for the manifest content (Graneheim \& Lundman, 2004); that is, visible and obvious components of what each SCR indicated about race or cultural factors, and a line-by-line coding of the document was conducted. Reviewing and rereading each SCR enabled us to formulate four emerging themes concerning how race, religion and cultural factors were directly or indirectly engaged with in the analysis, namely: 1) Understanding the child's views, feelings and vulnerabilities, 2) A consideration of culture, religion and socio-economic factors, 3) The role of race in interactions between the families and professionals, and 4) Abuse within the cultural contexts of faith.

\section{Findings}

In each of the SCRs, there was a noticeable absence of professional curiosity about the everyday lives of the children. Notably, the lived experiences and emotional lives of children were not known to professionals (Radford, 2010; Lock, 2011; Ibbetson, 2013; Carmi, 2014; Smith, 2014; Trench \& Miller, 2014; Miller, 2015; Trench, 2015; Leslie, 2015; NSPCC, 2017; North East Lincolnshire, LSCB 2017; Wate, 2017; Wiffin, 2017), particularly, their daily realities (Wiffin, 2017), the effects of cultural values and beliefs on child-rearing (Wate, 2017) and the impact of parental financial hardship (Carmi, 2014). As the SCR on Poppy Widdison stated: 'no single practitioner or service knew what life was like for T...' (North East Lincolnshire 
LSCB, 2017, p.14-15). This absence of knowledge applied to both children living with their biological parents, as well as children on a Special Guardianship Order (SGO), such as Shi-Anne Downer and Shanay Walker (Wate, 2017; Wiffin, 2014). As Shi-Anne Downer's SCR noted, 'after the SGO was granted, she became almost invisible to professionals' (Wate, 2017, p.28). In the section that follows, we explore this lack of professional curiosity with a focus on understanding the child's views, feelings and vulnerability, as well as the cultural, religious and socio-economic contexts.

\section{Understanding of the Child's Views, Feelings and Vulnerability}

In order to fully comprehend the needs of black children practitioners must have an understanding of their views, feelings and lived experience, gained through play, talking and observation (Sidebotham et al., 2016). In the SCRs examined, there was little evidence that the views of the child were known and their feelings understood, which raises questions about the level of importance professionals attach to children's voices. Several themes emerge. First, often the child was not spoken to alone (Radford, 2010; Lock, 2011; Ibbetson, 2013; Smith, 2014; Trench \& Miller, 2014; Miller, 2015; Wate, 2017), or in some cases, not always spoken to at all (Wiffin, 2017). Second, the use of a family member or neighbour as an interpreter with nonEnglish speaking children prevented the child's voice from being heard (Lock, 2011; Trench \& Miller, 2014). Third, for Khyrah Ishaq and some of her siblings, their

removal from state education to home schooling, meant that, 'They were isolated, effectively removing their rights to be seen, heard, or protected' (Radford, 2010, p.90). Fourth, for many children, there was no indication that the child's wishes and 
feelings had been sought (Radford, 2010; Lock, 2011; Ibbetson, 2013; Smith 2014; Trench \& Miller, 2014; Miller, 2015; Wate, 2017; Wiffin, 2017). Fifth, a professional focus on the caregiver/Special Guardian rather than the child, resulted in the child's voice being missed (Radford, 2010; Wate, 2017; Wiffin, 2017).

Let us take the example of Child $\mathrm{H}$, who died from physical injuries while in the care of his father. The SCR identifies 'the range, availability and quality of interpreters' (Trench \& Miller, 2014, p.15) as key issues impacting on the support provided and the quality of assessments (Trench \& Miller, 2014) which were critically problematic for communication with Child $\mathrm{H}$. At the child protection medical examination, as the interpreter did not arrive, the father, 'the possible person of concern", acted as the child's interpreter and spokesperson; (Trench \& Miller, 2014, p.25), which contributed to a lack of understanding of Child H's views, feelings and experience, and of the risk his father posed to him. Significantly, the SCR on Child H (Trench \& Miller, 2014) does not explore the social worker's thinking process that led to child $\mathrm{H}$ not being provided with an opportunity to speak through an interpreter, as soon as possible afterwards.

Effective communication is vital to engaging black families and safeguarding children, including the use of interpreters for communicating with asylum seeking, trafficked and other black children whose first language is not English (Laming, 2003; Welbourne, 2002; DfE, 2011; BAWSO, 2012; NSPCC, 2013; Westwood, 2016; DfE, 2017). While concerns about the availability of interpreting services are not new (Brandon et al.,1999; Welbourne, 2002; Brophy et al., 2003), analysis of how social workers made a professional judgement to use a neighbour or relative to 
interpret is missing from these SCRs. Crucially, the SCRs could have interrogated why some professionals are attaching insufficient importance to children's views and feelings, so that such lessons may inform future practice.

A common theme identified was the failure of professionals to understand the risks to and vulnerability of older black children, together with a racialised and gendered discourse about both boys and girls (Ibbetson, 2013; Leslie, 2015; Miller, 2015; Trench, 2015; Coventry Safeguarding Children Board, 2015; NSPCC, 2017). Frequently, the vulnerability of black boys was not understood and assumptions were made, which resulted in black boys not being seen as in need of protection (Ibbetson, 2013; Leslie, 2015; Miller, 2015; NSPCC, 2017).

Take, for example, the SCR of Child M, a 14-year-old boy that had gone missing (Miller, 2015). Significantly, rather than being viewed as a 'vulnerable' child, M was viewed by professionals and the police as 'a streetwise young man who knew exactly what he was doing' (Miller, 2015, p.35). This was coupled with an unfounded professional assumption of gang and drug involvement (Miller, 2015) and of Child M being able to protect himself from harm. Given what we know about the risks to children that go missing, including child sexual exploitation, gang involvement and victimisation, youth violence, and drug or alcohol misuse (Biehal \& Wade, 2002; Ofsted, 2013; Firmin \& Pearce, 2016), the SCR usefully questions how professionals view the risks to young black men and the robustness of services for children that go missing (Miller, 2015).

What the SCR does not explore is the process whereby professional assumptions and stereotypes became entrenched, nor to ask what mechanisms might have helped to 
challenge these fixed beliefs, to open them up to scrutiny and ensure anti-oppressive practice in the face of institutional and societal racism. The latter might include, for example, the role of organisational culture, professional supervision, self-reflexivity and training in achieving these goals. Lessons are not drawn on how professionals can be supported to question racialised and gendered assumptions about older black children, and to understand how these assumptions impact on understanding children's views and feelings, including vulnerability, risks, the impact of cumulative harm and risks of significant harm within extrafamilial contexts (Sidebotham et al., 2016; Firmin, 2018). Further, SCRs might usefully reflect on how professionals understand and respond to extra-familial risks. In the next section, we examine how SCRs considered the child's cultural, religious and socio-economic contexts.

\section{Consideration of Culture, Religion and Socio-Economic Factors}

A recurring theme threading through the SCRs is how information about the ethnicity of the child and families was considered. Indeed, the ethnicity of the child was often missing, incomplete, inconsistent or difficult to find. This is supported by findings from a number of studies (Ofsted, 2011; Brandon et al., 2012; Bhatti-Sinclair \& Price, 2016, Sidebotham et al., 2016). In the main, the SCRs consistently highlight a lack of professional curiosity about the children's lived experiences within their cultural and ethnic context. For the most part, though the ethnicity is stated in the SCRs, they tend not to comment in any meaningful way to gain an understanding of the lived experiences of the child. Most frequently, there is a tendency to state the child's ethnicity in broad terms without unpacking what that means for the day-to-day realities for the children within their ethnic and cultural context. For instance, the SCRs on Rachel and Poppy do not state their ethnicity (Lock, 2011; North East 
Lincolnshire LCSB, 2017); the SCR on Shanay Walker describes her as 'dual heritage' and her father and paternal relatives as 'ethnic minority' (Wiffin, 2017); while Shi-Anne Downer's ethnicity is given in broad terms as 'white British and Black African background' (Wate, 2017 p3), but the ethnicity of each parent and her Special Guardian is not stated. Likewise, inconsistency in how the family's ethnicity was recorded across agencies was also noted in the SCR on Kyrah Ishaq. The SCR stated:

'Overall, the family's ethnicity is described as black, with different members being recorded as black Caribbean, black African, or black British' (Radford, 2010 p27).

Not surprisingly, Kyrah Ishaq's SCR questions how information about ethnicity was obtained and whether the descriptions given reflect 'how individuals saw themselves and/or their children, or if they were professional interpretations' (Radford, 2010 p27).

Similarly, the SCR on Rachel highlights the absence of knowledge of the child and family's ethnicity, cultural background, language and dialect, and suggests:

'This family's culture, ethnicity and language was a significant factor for the professional interventions with the mother and her children. However for the short period of time that this SCR covers, no professional knew with any certainty what the cultural background 
was for the family or the actual language and related dialect which they used' (Lock, 2011 p9).

A key consequence of this is that in the absence of knowledge of the family's culture and language, the SCR noted that assumptions were made about the mother. More specifically, the SCR emphasise that, 'A failure to understand a family's race, culture, ethnicity and language will seriously impinge on a professional's ability to provide effective help to the parents and children' (Lock, 2011, p15).

Likewise, the SCR on $\mathrm{CH}$, a 15-year-old young man who stabbed a man, has as part of the terms of reference: 'Was practice sensitive to and/or influenced by the racial, cultural, gender, sexuality, linguistic and religious identity and any issues of disability of the child and family, and were they explored, taken on board and recorded?' (Leslie, 2015 p21). While these are important questions to pose, insufficient analysis is provided about these aspects of the family's life to enable a fuller picture of the home environment for $\mathrm{CH}$ from which lessons may be learned.

In some senses, where all facets of the child's racial and ethnic identity were considered in the SCR, insights were provided to show some aspects of the racialised experiences of children. For example, the SCR on Child $\mathrm{CH}$, has been useful in reflecting on the issue of 'positive black role models' (Leslie, 2015 p16), while the SCR into Child F, a 15-year old looked-after child who hung himself in a Young Offender Institution, includes a detailed consideration of his sense of racial identity and the confusion he felt in relation to it (Ibbetson, 2013). Indeed, Child F's SCR noted that he was the only child in his household who was of mixed parentage, that he 
considered himself to be white, and that he found it very difficult to accept that he was perceived as black (Ibbetson, 2013). The SCR makes a strong link between his confusion over his racial identity and other difficulties including 'poor self-esteem', 'recklessness', 'criminal behaviour', 'risk of self-harm' (p20) and adjustment to the Young Offender Institution, with race and ethnicity important factors influencing how young people interacted with each other. The report illuminates how Child F's placement with 'a white family in a predominantly white area' and the failure to nurture his racial identity development elevated his vulnerability (p20). Although these examples are significant exceptions, the overall picture that emerges from the majority of the SCRs is of insufficient professional curiosity regarding the children's racial and ethnic identities, and experience of racism.

As previously highlighted, commonly overlooked aspects in many of the SCRs are the lack of deep probing of the ways multiple inequalities coalesce to structure the lived experiences associated with the parenting environment for black children. Take the example of Jamilla, who died from malnutrition as a result of chronic neglect. Her mother experienced a range of adverse childhood experiences (ACE) (Bellis et al., 2014), including cumulative trauma; being a victim of forced marriage at age 14; rape, and domestic violence. Additionally, at age 18, she was already the mother of three children under the age of 5, conceived in circumstances not of her choice, and without strong relationships or support networks. The SCR of Jamilla found that her mother was also in financial hardship, as she was not receiving child benefit for her two older children as a result of their Somaliland birth certificates not being accepted as proof that they were her children (Carmi, 2014). Yet, the fact that her main source of support was the very same family that forced her into a child marriage was not 
questioned in the SCR as being a risk factor. Certainly, the SCR highlights that Jamilla's mother had complex needs as a result of trauma across the lifespan intersecting with economic disadvantage. The SCR noted:

The impact for mother of being of dual heritage the impact of the abuse she had suffered; impact on her of being deprived of the teenage experiences she may have grown up expecting prior to her move to Somaliland at the age of 12; attitude of the maternal family to mother given she had left her husband' (p55)

It seems, though, that how such dynamics would have unfolded for Jamilla's mother which may have contributed to the tragic outcomes for Jamilla, were not delved into deeply in the SCR to extract learning about what it is like for a child experiencing the effects of multiple layers of oppression. The SCR stated:

Given that she had fled a forced marriage arranged by her family this was a relevant area to explore, especially given mother's reliance on these relatives for frequent and regular support.' (p8)

Importantly, Jamilla's SCR alludes to the extremes of need resulting in many layers of complexities, which contributed to the invisibility of her and her siblings to professional helpers. At the same time, it could be argued that questions about the complex linkages of race, gender and cultural beliefs that have directly contributed to Jamilla's mother's circumstances and fundamentally impacted her mental health and her capacity to parent, did not receive probing analysis in the SCR. For example, 
relatively little attention has been given to the cumulative and interactional impacts of these issues in the SCR, which did not draw out the intersecting effects of the environmental, family, and parenting factors that influenced Jamilla's mother's negligent parenting.

Thus, the important lessons about the challenges and complexities involved in making comprehensive assessments of the risk factors in cases that are deeply rooted in culture-specific practices are not articulated very clearly. Instead, there needs to be recognition of the ways that race, gender and religious beliefs intersect to add a range of complex risks in the parenting environment for black children.

\section{Role of Race in Interactions Between Parents, Children and Professionals}

A number of the SCRs examined the role of race, to a certain degree, when analysing interactions between parents and professionals. The SCR of Child M, age 14, is significant in questioning the impact of ethnicity and gender in the service response when Child M went missing (Miller, 2015). In another example, the SCR of Rachel raises some important considerations regarding the dynamics between black and minority ethnic families and professionals. The point is made that care must be taken to ensure that 'cultural deficit', a lower threshold 'of concern and intervention' (Lock, 2011 p15) is not applied to black and minority ethnic families. This SCR made several significant recommendations, including developing 'best practice guidance' in respect of safeguarding newly arrived immigrant children, with a particular focus on the needs of those families who do not have 'recourse to public funds' (p15). It also called for 'a coherent policy' regarding 'the use of interpreters' (p15); 'an evaluation of preventative services that exist in communities with identified high numbers of 
BME and immigrant families', including whether they are able 'to respond to the cultural make-up of the locality', 'are adaptable to changing needs' and 'do not work on different thresholds for intervention than other localities' (p16).

The picture is further complicated for some children whose families had uncertain immigration status (e.g. Leslie, 2015; Lock, 2011; Smith, 2014; Trench \& Miller, 2014). For example, the SCR on 15-year-old $\mathrm{CH}$, whose family were asylum-seekers from Jamacia, highlights concern that the professional contact with the family failed to identify that his mother was 'prioritising her immigration issues above her responsibilities as a parent' (Leslie, 2015). The SCR emphasised that the 'subtleties and complexities of CH's case was not recognised or addressed' (Leslie, 2015, p12). Mostly, the SCRs do not dig deep enough to consider the convergence of insecure immigration status with additional factors in relation to deprivation that can increase risk factors for children with multiple and complex vulnerabilities.

\section{Abuse Within the Cultural Context of Faith}

A recurring theme in a number of the SCRs studied is the role of religious beliefs in framing the familial environment for the children involved (Radford, 2010; Trench \& Miller, 2014; North East Lincolnshire LCSB, 2017; Wiffin, 2017). However, the SCRs suggest this is rarely explored in assessments and where it is referred to in the SCRs is not analysed critically, to consider how it may have contributed to the outcomes for the children. For instance, in the SCR on Khyrah Ishaq (Radford, 2010), the mother's male partner's beliefs in spirit possession, stemming from his interpretation of Islam, is identified as leading to the 'severe physical chastisements, beatings, humiliating punishments and the withdrawal of food' that she suffered, 
because he believed that 'evil spirits inhabited the child' (p33). Available evidence suggests that deeply embedded religious beliefs that intersect with cultural traditions can play a key role in increasing spirit possession accusations against children (Stobart, 2006; Tedam \& Adjoa, 2017; Briggs \& Whittaker, 2018). Analysis in Kyrah Ishaq's SCR might have emphasised the delicate balance between respecting parents' religious beliefs whilst asking the difficult questions for making risk assessments in situations of child abuse linked to beliefs in witchcraft and spirit possession. Khyrah Ishaq's SCR could have extracted the learning about professional curiosity in this complex area where social workers have to make hard professional judgements that involve challenging parents when they use their religious beliefs as a justification for harmful behaviours, while also having to support and assist them in their parenting role in order to ensure the protection of children. As Sidebotham et al., (2016) points out, there are inherent tensions in the need for professionals to be sensitive to parents' beliefs, whilst at the same time being prepared to challenge parents to enable robust risk assessments.

In other cases, cultural and religious beliefs merge in complex ways. Shanay Walker, was a 7-year-old mixed ethnicity child (her mother is listed as white and her father as an 'ethnic minority'), who died from a brain injury as a result of the physical violence suffered at the hands of her Guardian (her paternal aunt), and her paternal grandmother (Wiffin, 2014); both the aunt and grandmother were jailed for child cruelty. In Shanay's SCR, it is implied that some of her treatment may have been related to the aunt's cultural heritage (Wiffin, 2014), though the assertion is not sufficiently explained, so we do not know what it actually refers to. A further issue concerns the way that the aunt's parenting style is referred to as harsh and punitive; 
the SCR emphasises that she drew on the guidance and support of 'spiritual guardians' from her church to implement a strict parenting style to discipline Shanay for her 'behavioural and conduct problems' (p48). More worryingly, despite Shanay repeatedly presenting at school with bruises and other injuries, the professionals involved did not ascertain the actual nature of the aunt's strict discipline methods. The SCR thus concluded that the professional judgements made did not distinguish between 'what constitutes effective approaches to discipline as opposed to punishment' (Wiffin, 2014 p48). Generally speaking, there is a lack of analyses of the interacting risk factors that the practitioners had to weigh up in making complex judgements about thresholds so the lessons that can be learnt about undertaking childfocused assessments to elicit an accurate picture about what was going on for these children are not explicitly drawn out.

\section{Discussion and Conclusions}

This paper has sought to examine the way that race is considered in SCRs involving black children. One striking observation is the variability in the recording of children's race and ethnicity in the SCRs. Consequently, the racialised and cultural lived experiences of the children, are an underdeveloped area in the majority of the SCRs examined in this paper. At the same time, it is important to note the heterogeneity of black children's backgrounds in the SCRs reviewed. Thus, a more nuanced understanding of the differentiated child-rearing practices which can result in black children being at elevated risk of particular kinds of maltreatment is required (AUTHOR, 2016; Bhatti-Sinclair \& Price, 2016). As such, there was a lack of professional curiosity in understanding the salience of race in the children's lives, which means that the powerful influence of race on black children's interaction with 
the child protection system is rarely explored sufficiently so the lessons for learning and improvement in addressing cultural, racial and religious experiences are not accentuated. Brandon et al., (2012) has articulated concerns that the lack of analysis of race may serve to limit practitioners' capacities to assess the complex and multilayered issues that have to be navigated to engage resistant families. Sidebotham et al., (2016) reinforce the point that SCRs should 'provide a narrative of the child's and the family's experience within a cultural and racial context' (p217) so that we can understand what went wrong for the child.

Routinely, recommendations are made in the SCRs about reviewing multi-agency training and improving supervision on race to develop practice for working with black families. Undeniably, training and good supervision are key components in supporting and sustaining practitioners' professional knowledge and skills to navigate the inherent tensions that are engendered in child protection work with families where abuse is intertwined with parents' cultural and religious practices. These issues are significant as training may help with insights to be gained by attending to the challenges that practitioners are faced with when working with complex cases. Equally, it is important to address how to help practitioners be cognisant of the potential influence of their beliefs and unconscious biases about other races and cultures that might inhibit professional curiosity about black children's lived experiences. Put another way, this may help practitioners improve their professional confidence to provide critical analysis of the issues arising when they have to make complex professional judgements in situations where caregivers justify their actions on cultural beliefs and practices that have harmful consequences (AUTHOR, 2016). Crucially, in order to develop relationship-based parenting support with black 
families, lessons must be learned from SCRs to support practitioners to have difficult conversations about race and cultural beliefs where abuse is alleged or suspected. As such, more nuanced interrogation of the factors that influence the familial and social environments of black children is needed for developing effective interventions. It remains to be seen how the new arrangements set out in the Children and Social Work Act 2017, for Child Safeguarding Practice Review Panel and Child Death Review Partners will address the poor reporting of children's ethnicity, and in particular to how issues of race and cultural factors are addressed in SCRs.

To be clear, we are not suggesting that any of these deaths could have been anticipated or prevented. How to manage complex child protection cases in a context of diminished resources is a very real challenge for children's services (Bilson \& Martin, 2017; Bywaters et al., 2017). Notwithstanding, attempts to intervene and change the conditions of children's lives to reduce the incidence of child maltreatment and minimise the likehood of similar deaths happening, must be grounded in a critical interrogation of how race, ethnicity, gender, class, religion and immigration status converge for black children in their intra and extra-familial environments.

\section{References}

Barn, R. (2007) "Race", Ethnicity and Child Welfare: A Fine Balancing Act, British Journal of Social Work, 37(8), 1425-1434.

Barn, R. \& Kirton, D. (2016) Safeguarding Black Children: An Exploration of Physical Abuse. In Safeguarding Black children: Good Practice in Child Protection (eds C. Bernard \& P. Harris), pp 111-127. Jessica Kingsley Publishers, London.

BAWSO (2012) Protecting Black and Minority Ethnic Children: An Investigation of Child Protection Investigations. BAWSO, Cardiff. 
Bellis, M. A. Hughes, K. Leckenby, N. Perkins, C \& Lowey, H. (2014b) National Household Survey of Adverse Childhood Experiences and their Relationship with Resilience to Health-Harming Behaviors in England. BMC Medicine 12(72), 1-10.

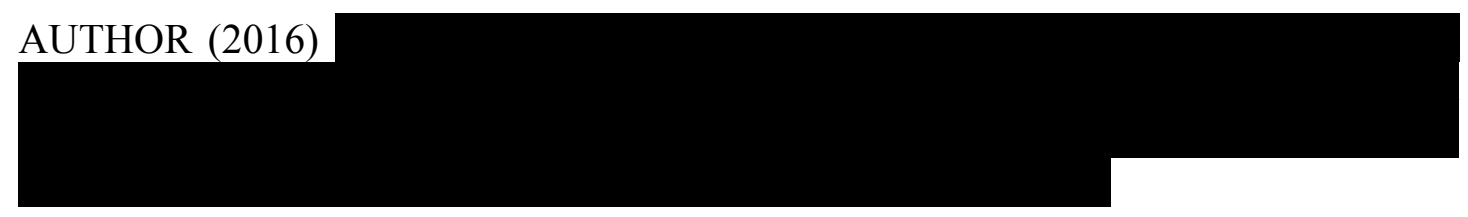

AUTHOR (2016)

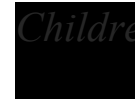

Bhatti-Sinclair, K. \& Price, D. (2016) Evaluation: Serious Case Reviews and Antiracist Practice. In: Social Work in a Diverse Society: Transformative Practice with Black and Minority Ethnic Individuals and Communities (eds C.Williams \& M. J. Graham), pp. 217 - 228. Policy Press, Bristol.

Biehal, N. \& Wade, J. (2002) Children Who Go Missing: Research, Policy and Practice. Department of Health, London.

Bilson, A. \& Martin, K E. C. (2017) Referrals and Child Protection in England: One in Five Children Referred to Children's Services and One in Nineteen Investigated before the Age of Five. British Journal of Social Work, 44, 3, 793-811.

Blom-Cooper, L. (1985) A Child in Trust: The Report of the Panel of Inquiry into the Circumstances Surrounding the Death of Jasmine Beckford. London Borough of Brent, London.

Brandon, M., Sidebotham, P., Bailey, P., Belderson, P., Hawley, C., Ellis, C. \& Megan, M. (2012) New Learning From Serious Case Reviews: A Two Year Report for 2009-2011. Department of Education, London.

Brandon, M., Bailey, S., Belderson, P., Gardener, R., Sidebotham, P., Dodsworth, J., Warren, J. \& Black, J. (2009) Understanding Serious Case Reviews and their Impact: A Biennial Analysis of Serious Case Reviews 2005-7. Research report DCSF-RR129. Department for Children, Schools and Families, London.

BRAP (2011) Child Protection and BME Communities: A Conference Report. BRAP, Birmingham.

Briggs, S. \& Whittaker, A. (2018) Protecting Children from Faith-Based Abuse through Accusations of Witchcraft and Spirit Possession: Understanding Contexts and Informing Practice. British Journal of Social Work. The British Journal of Social Work, bcx155, https://doi.org/10.1093/bjsw/bcx155

Published:18 January 2018 
Brophy, J., Jhutti-Johal, J. \& Owen, C. (2003) Significant Harm: Child Protection Litigation in a Child Protection Setting. Lord Chancellor's Department Research Unit, London.

Bywaters, P. Brady, G. Bunting, L. Daniel, Featherstone, B. Jones, C. Morris, K. Scourfield, J. Sparks, T. Webb, C. (2018) Inequalities in English Child Protection Practice Under Austerity: A Universal Challenge? Child \& Family Social Work, 23, 1, 53-61.

Carmi, E. (2014) 'Jamilla': Serious Case Review. Tower Hamlets Safeguarding Children Board, Tower Hamlets.

Chand, A. (2003) Race and the Laming Report on Victoria Climbié: Lessons for Inter-Professional Policy and Practice, Journal of Integrated Care, 11(4), 28-37.

Coventry Safeguarding Children Board (2015) Serious Case Review. Child G, Child H, Child I, Child J, Child K. Coventry Safeguarding Children Board, Coventry.

Department for Education (2017) Care of unaccompanied migrant children and child victims of modern slavery: Statutory guidance for local authorities. Department for Education, London.

Department for Education (2013) Statistical Release: Child Death reviews: Year Ending 31 March 2013, London: Department for Education.

Department for Education (2011) Safeguarding children who may have been trafficked: Practice guidance. Department for Education, London.

Firmin, C. \& Pearce, J. (2016) Living in Gang-Affected Neighbourhoods: The Impact on Black Children and Young People. In: Safeguarding Black Children: Good Practice in Child Protection. (eds C. Bernard \& P. Harris), pp 76-90. Jessica Kingsley Publishers, London.

Firmin, C. (2018) Contextualizing case reviews: A methodology for developing systemic safeguarding practices, Child and Family Social Work, 23, 45-52.

Garrett, P. M. (2006) Protecting Children in a Globalised World: 'Race' and 'Place' in the Laming Report on the Death of Victoria Climbe, Journal of Social Work, 6(3), 315-336.

Graneheim, U.H. Lundman, B. (2004) Qualitative Content Analysis in Nursing Research: Concepts, Procedures and Measures to Achieve Trustworthiness. Nurse Education Today, 24, 105-112.

Hall, E. L. \& Rammell, K. (2017) Racial-and Ethnic-Sensitive Practice: From the Practitioners' Perspective. Journal of Social Work, 17(6), 678-694. 
Haringey Local Child Safeguarding Board (2010) Serious Case Review, 'Child A', March 2009. Department for Education, London.

Hsieh, H-F. \& Shannon, S. E. (2005) Three Approaches to Qualitative Content Analysis, Qualitative Health Research, 15(9), 1277-1288.

Ibbetson, K. (2013) Serious Case Review Executive Summary. Services provided for Child F June 2004 - January 2012. Tower Hamlets Safeguarding Children Board, Tower Hamlets.

Jones, D.N. (2015) Serious Case Reviews in Child Protection: Historical Reflections, The Virtual Staff College.

Laming, Lord. (2003) The Victoria Climbié Inquiry: Report of an inquiry by Lord Leslie, A. (2015) Serious case review overview report: Child ' $\mathrm{CH}$ '. Enfield Safeguarding Children Board, Enfield.

Lock, R. (2011) Serious Case Review. Executive Summary Re SCR 13/10. Gloucestershire Safeguarding Children Board, Gloucestershire.

London Borough of Lambeth (1987) Whose Child? The Report of the Public Inquiry into the Death of Tyra Henry, London Borough of Lambeth.

Mayring, P. (2000) Qualitative Content Analysis. Forum: Qualitative Social Research. $1(2)$

Miller, G. (2015) Overview report in respect of Child M: a 14 year-old teenager. Croydon Safeguarding Children Board, Croydon.

Newham Area Child Protection Committee (2002) Ainlee Born 24.06.1999 Died 07.01.2002 Chapter 8 Review. Newham Area Child Protection Committee, London.

North East Lincolnshire LSCB (2017) Serious Case Review Report Child T. North East Lincolnshire Local Safeguarding Children Board, Lincolnshire.

NSPCC (2013) NSPCC Briefing: Learning from Serious Case Reviews Involving People whose First Language is Not English. NSPCC, London.

NSPCC (2017) Serious Case Review No. 2017/C6344. NSPCC, London.

Ofsted (2011) The Voice of the Child: Learning Lessons from Serious Case Reviews April 2011, www.ofsted.gov.uk/publications/100224

Parton, N. (2004) From Maria Colwell to Victoria Climbie: Reflections on Public Inquiries into Child Abuse a Generation Apart, Child Abuse Review, 13, 80-94.

Pearce, J. (2014) What's Going On' to Safeguard Children and Young People from 
Child Sexual Exploitation: A Review of Local Safeguarding Children Boards' Work to Protect Children from Sexual Exploitation, Child Abuse Review, 23, 159-170.

Radford, J. (2010) Serious Case Review under Chapter viii 'Working Together to Safeguard Children' in respect of the Death of a Child Case Number 14. Birmingham Safeguarding Children's Board, Birmingham.

Rapport, F. (2010) Summative Analysis: A New Qualitative Method for Social Science and Health Research. International Journal of Qualitative Methods: Archive. 9, 3. 270-290.

Rawlings, A., Paliokosta, P., Maisey, D., Johnson, J., Capstick, J. \& Jones, R. (2014) A Study to Investigate the Barriers to Learning from Serious Case Reviews and Identify ways of Overcoming these Barriers. Department for Education, London.

Rustin, M. (2004) Learning from the Victoria Climbie Inquiry, Journal of Social Work Practice, 18(1), 9-18.

Sidebotham, P., Brandon, M., Bailey, S, Belderson, P., Dodsworth, J., Garstang, J., Harrison, E., Retzer, A. \& Sorensen, P. (2016) Pathways to harm, pathways to protection; a triennial analysis of serious case reviews 2011 - 2014. Department for Education, London.

Smith, F. (2014) Serious Case Review: 'Zara'. Wandsworth Safeguarding Children Board, Wandsworth.

Stobart, E. (2006) Child Abuse Linked to Accusations of "Possesion" and "Witchcraft". Department of Education and Skills, Nottingham.

Tedam, P. and Adjoa, A. (2017) The W Word: Witchcraft Labelling and Child Safeguarding in Social Work Practice. Critical Publishing, St Albans.

Trench, S. (2015) Serious case review report: Child R. Southwark Safeguarding Children Board, Southwark.

Trench, S. \& Miller, G. (2014) Serious Case Review: Child H. Lambeth Safeguarding Children Board, Lambeth.

Wate, R. (2017) Serious Case Review. Shi-Anne Downer (Birth Name). AKA Keegan Downer. Born on $9^{\text {th }}$ March 2014. Died on $5^{\text {th }}$ September 2015 age 18 months. Case Identifier BSCB 2015-6/2. Birmingham Safeguarding Children Board, Birmingham.

Welbourne, P. (2002) Culture, Children's Rights and Child Protection, Child Abuse Review, 11(6), 345-58.

Westwood, J. (2016) Safeguarding Unaccompanied Asylum-Seeking Children: Promoting Rights and Strengths-Based Practice. In Safeguarding Black children: Good Practice in Child Protection (eds C. Bernard \& P. Harris), pp 239-252. Jessica Kingsley Publishers, London. 
Wiffin, J. (2017) Serious Case Review Child J. Nottingham City Safeguarding Children Board, Nottingham.

Zhang, Y. \& Wildemuth, B. M. (2017) Qualitative Analysis of Content. In Applications of Social Research Methods to Questions in Information and Library Science (2 ${ }^{\text {nd }}$ Edition) (ed. B.M. Wildemuth), pp 318-330. Libraries Unlimited, California. 